\title{
PARÁMETROS DE CALIDAD DE PRODUCCIÓN DE BIOGÁS A PARTIR DE PULPA DE CAFÉ
}

\author{
QUALITY PARAMETERS OF BIOGAS PRODUCTION COFFEE PULP
}

\section{Yuly Andrea Quinchía-Jaramillo}

Estudiante de Ingeniería Ambiental Universidad Nacional Abierta y a Distancia UNAD

\section{yaquinchiaj@unadvirtual.edu.co}

\section{Johana Pérez-Serna}

Estudiante de Ingeniería Ambiental Universidad Nacional Abierta y a Distancia UNAD

jperezse@unadvirtual.edu.co

\section{Gloria María Doria Herrera}

Químico, Magister en Ciencias - Química, candidata a Doctor en Ingeniería Ambiental, Docente ocasional Universidad Nacional Abierta y a Distancia UNAD

gloria.doria@unad.edu.co

\section{Yesid Sánchez Acosta}

Ingeniero Biológico, Magister en Ciencias Biotecnología. Universidad Nacional de Colombia.

\section{RESUMEN.}

La generación e inadecuado manejo de los residuos de la industria cafetera, dependiendo del tipo de procesamiento y siendo la vía húmeda de las más populares, representa importantes afecciones a los cuerpos de agua y suelo, debido a que esta es arrojada a dichas fuentes sin ningún tipo de tratamiento. Dentro de las opciones más versátiles para el aprovechamiento de estos residuos agroindustriales generados se destaca la digestión anaerobia. La digestión se caracteriza por ser una tecnología DOI: https://doi.org/10.22490/26653176.3521 


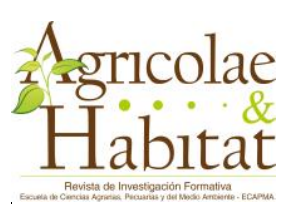

sostenible ya que las bacterias anaerobias que allí yacen son capaces de transformar este residuo en metano, que es combustible de valor agregado y más para zonas de difícil acceso. En esta investigación, se realizó una revisión sobre estudios reportados con relación a las principales variables que generan un impacto en la aplicación de la tecnología. Para lograrlo, se realizó una búsqueda de artículos en buscadores y bases de datos especializados, se aplicó la metodología PRISMA para la selección de los mejores estudios y con ello se realizaron conclusiones para la aplicación de esta a nivel experimental. Se encontró que entre 30 a $40^{\circ} \mathrm{C}$ es la temperatura óptima, que el pH tiene un rango de trabajo que oscila entre 6.8 a 7.2, la agitación se sugiere de media a baja velocidad con el propósito de promover homogeneidad dado que una excesiva agitación puede destruir los agregados bacterianos, inoculación depende de la materia orgánica y finalmente la inoculación, es requerida debido a que este tipo de residuos no poseen poblaciones bacterianas metanogénicas, por esta razón, siempre se requiere la incorporación de inóculos para la optimización del proceso.

Palabras Clave: biodigestor; aprovechamiento residuos agroindustriales; biodigestión; metabolismo anaerobio

\section{ABSTRACT.}

The generation and inadequate management of waste from the coffee industry, depending of kind processing and being the most popular wet road, represents significantly effects on the water and soil, because it is thrown into these sources without any type of treatment. Among the most versatile options for the use of these agroindustry waste generated, anaerobic digestion. The anaerobic digestion is characterized by being a 


\section{Astricolae \\ Habitat}

sustainable technology since the anaerobic bacteria that lie there can transform this residue in methane, which is possible consider like fuel of added value and more for hard-to-reach areas. In this research, did a review was conducted on reported studies in relation to the main variables that generate an impact on the application of technology. To achieve this, a search of articles in search engines and specialized databases was carried out, the PRISMA methodology was applied for the selection of the best studies and with-it conclusions were made for the application of this at the experimental level. It was found that between 30 to $40^{\circ} \mathrm{C}$ is the optimum temperature, that the $\mathrm{pH}$ has a working range that ranges from 6.8 to 7.2 , agitation is suggested from medium to low speed with the purpose of promoting homogeneity since excessive agitation can destroying bacterial aggregates, inoculation depends on organic matter and finally inoculation, it is required because this type of waste does not have methanogenic bacterial populations, for this reason, the incorporation of inoculums is always required for process optimization.

Keywords: biodigester; use of agroindustry waste; bio-digestion; anaerobic metabolism.

\section{INTRODUCCIÓN.}

El aumento en la explotación de los recursos naturales, además de un modelo de crecimiento basado en el consumo no sostenible, ha provocado un incremento en la generación de residuos que constituyen un problema de primer orden. A esta problemática se le suma, las consecuencias del cambio climático, el aumento de la demanda mundial de los combustibles fósiles, la inseguridad energética, y la explotación continua de los recursos naturales limitados demandan el desarrollo de alternativas de 
tratamiento que proporcionen soluciones integrales, aplicando métodos que alivien la presión sobre los recursos naturales y representen una opción de generación energética (Llamas, 2014).

En particular, Colombia presenta una problemática muy similar a la de otros países productores de café, en donde se utiliza la vía húmeda como proceso de beneficio; método que involucra una serie de operaciones (despulpado, remoción del mucílago por fermentación natural o remoción mecánica, lavado y secado) para transformar los frutos en café pergamino de alta calidad física y en taza. Estas operaciones generan subproductos (pulpa, cáscara, mieles) que pueden ocasionar un aumento considerable de la contaminación orgánica, concentración de materia suspendida, generación de olores desagradables, turbidez y pérdida de la calidad del agua y suelo cuando son arrojados directamente a estos ecosistemas (Guardia, 2012).

En este contexto, tal como se explica en la figura 1, en la digestión anaerobia, se da la degradación y estabilización de residuos domésticos e industriales, considerada un proceso biológico que convierte sustratos complejos en biogás por acción microbiana en ausencia de oxígeno, también consideradas bacterias anaerobias (Teperino et al., 2017). 


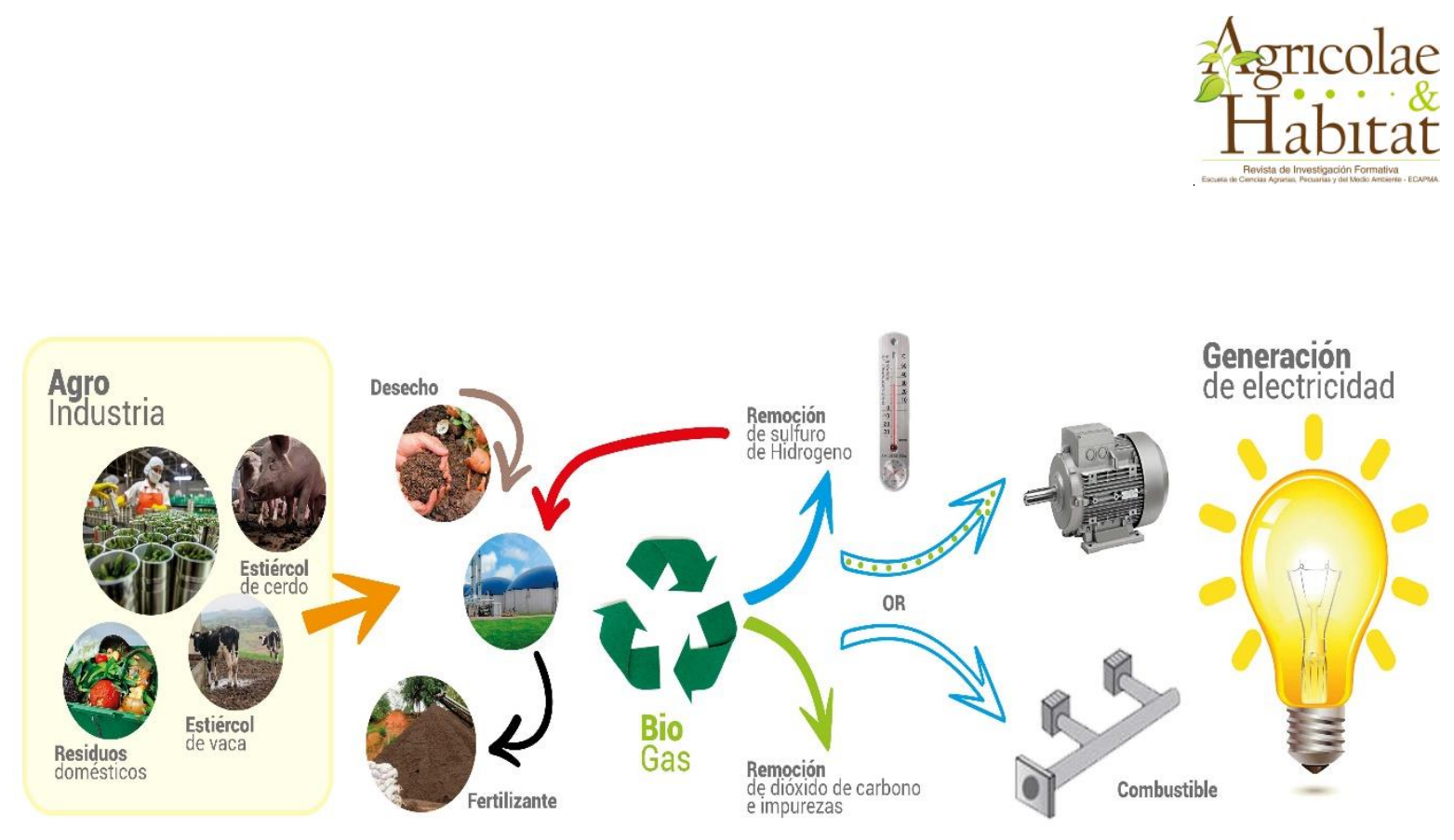

Figura 1. Diagrama general del proceso de digestión anaerobia. Fuente: los autores

En este artículo, se presentan las variables que afectan el proceso de digestión anaerobia de la pulpa de café, tomando como referencia artículos publicados con la temática aplicando palabras claves, buscadores booleanos y el uso de motores de búsqueda que permitieron seleccionar los mejores trabajos relacionados, luego de ello se aplicó la metodología planteada en el metaanálisis denominada metodología PRISMA, para discriminar los artículos usados para las conclusiones obtenidas.

\section{METODOLOGÍA.}

En la Figura 2 se explica de forma gráfica de la metodología para el desarrollo de la investigación, inicialmente se inicia con la elección de las palabras claves, las cuales fueron: "anaerobic digestión and coffee", "coffee and husk", "coffee pulp" y "anaerobic digestion"; esta elección se debió a la frecuencia de uso de estos términos en la literatura previamente analizada. Como conectores en la búsqueda se usó el operador booleano "AND", ya que este permitió darle un orden lógico a la búsqueda y tomar en cuenta los términos coincidentes en todos los campos de investigación. 
Secuencialmente en la búsqueda, se utilizó Google Académico (Google Scholar), Scielo, ScienceDirect, Scopus, Redalyc, Dialnet y Proquest, mediante un filtro para seleccionar los artículos publicados entre 2010 2018.
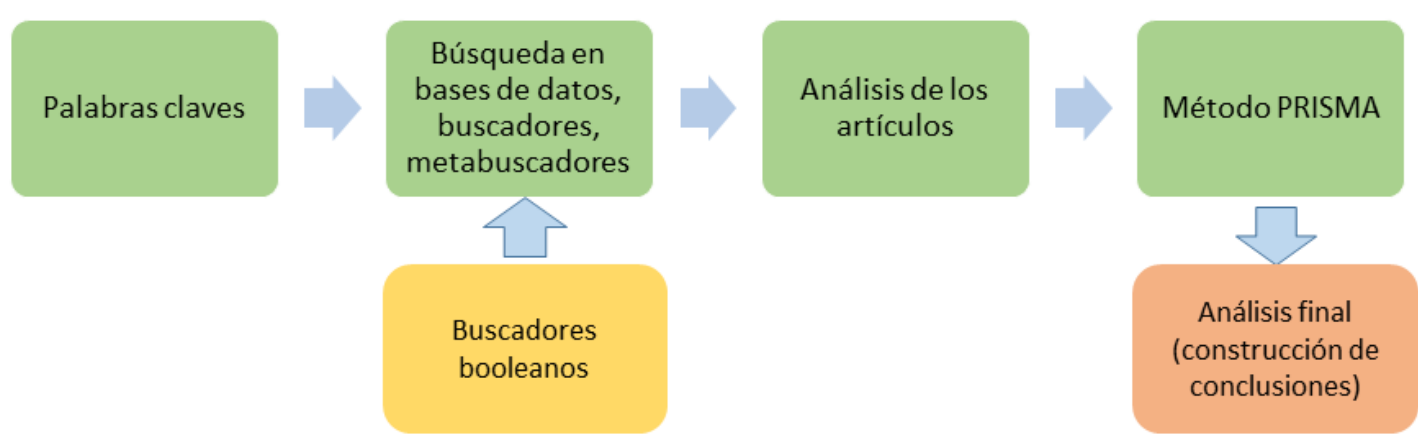

Figura 2. Etapas metodologicas del trabajo de investigación. Fuente: los autores

Para el desarrollo de esta investigación, se empleó la metodología PRISMA, la cual consiste en una revisión sistemática de literatura donde se identificó y evaluó los estudios del mismo tipo con un objetivo común. Dichos estudios brindan un resumen fiable, válido y actualizado de la mejor evidencia científica disponible, convirtiéndose en la fuente científica más segura para la toma de decisiones (Vélez \& Meneses, 2013; Huttom et al., 2016). Para llevar a cabo la metodología PRISMA se tuvieron en cuenta 7 elementos (título, DOI, fundamento, metodología, selección de estudios, recopilación de datos, riesgo de sesgo y conclusiones), los cuales fueron seleccionados teniendo en cuenta los aspectos de mayor relevancia en el área de interés de la investigación. En la Tabla 1 se muestran los aspectos evaluados y las puntuaciones asignadas para cada componente de estudio, la escala de valoración es de 1 a 5 tomando como 1 al aspecto menor valorado y 5 al aspecto mejor valorado. 
Tabla 1. Lista de comprobación de los elementos para evaluar en una publicación bajo la metodología PRISMA modificada para evaluación de artículos

\begin{tabular}{|c|c|}
\hline Ítem evaluado & Elemento de la lista de publicación \\
\hline Titulo & $\begin{array}{l}\text { Identificar el informe como una revisión sistemática, articulo de revisión o en efecto de } \\
\text { investigación relacionado con el tema de estudio. }\end{array}$ \\
\hline DOI & $\begin{array}{l}\text { El articulo posea Digital Object Identifier System, enlace permanente en forma de } \\
\text { código alfanumérico que identifica de forma única un contenido electrónico. }\end{array}$ \\
\hline Fundamento & Describir claramente los fundamentos que sustentan el artículo. \\
\hline Metodología & $\begin{array}{l}\text { Si el articulo posee un diseño experimental planeado, o en efecto un protocolo de } \\
\text { desarrollo experimental que acompañe la actividad investigativa. }\end{array}$ \\
\hline $\begin{array}{l}\text { Selección de } \\
\text { estudios }\end{array}$ & $\begin{array}{l}\text { Indicar el proceso de selección de estudios (por ejemplo, cribado, elegibilidad incluidos } \\
\text { en la revisión sistemática y, cuando corresponda, incluidos en el metaanálisis). }\end{array}$ \\
\hline $\begin{array}{l}\text { Recopilación } \\
\text { de datos }\end{array}$ & $\begin{array}{l}\text { Describir los métodos para la extracción de datos de las publicaciones (por ejemplo, } \\
\text { formularios pilotados, por duplicado, de forma independiente) y cualquier proceso para } \\
\text { obtener y confirmar datos por parte de los investigadores. }\end{array}$ \\
\hline Riesgo de sesgo & $\begin{array}{l}\text { Describir los métodos utilizados para evaluar el riesgo de sesgo en los estudios } \\
\text { individuales (incluyendo la especificación de si esto se realizó al nivel de los estudios o } \\
\text { de los resultados) y cómo esta información se utilizó en cualquier síntesis de datos. }\end{array}$ \\
\hline Conclusiones & $\begin{array}{l}\text { Proporcionar una interpretación general de los resultados en el contexto de otra evidencia, } \\
\text { y las implicaciones para la investigación futura }\end{array}$ \\
\hline
\end{tabular}

Además de los aspectos valorados en la metodología, se tomó como punto de estudio los artículos que mostraron mayores aportes conforme a la variable respuesta denominada para este caso calidad de biogás, expresada en rendimiento calorífico del mismo y volumen de metano por kilogramo de pulpa. Así mismo, estudios realizados sobre la productividad de metano haciendo uso de diversos sustratos seleccionados y los principales parámetros de operación para la digestión anaerobia como temperatura, $\mathrm{pH}$, inoculación, factores de inhibición y agitación.

\section{DISCUSIONES Y RESULTADOS}

La búsqueda en las bases de datos anteriormente mencionadas arrojó 113.904 referencias, de las que se seleccionaron 50 entre artículos científicos y tesis doctorales, esto en relación con su contenido y 
pertinencia con el tema a desarrollar. En la Figura 3 se evidencia que la mayoría de los hallazgos relacionados con las palabras claves se relacionan con Redalyc, seguido Proquest y otros, en lo que se destacan Science Direct y Scopus, bases de datos reconocidas. Con este precedente se concluye que la temática es principalmente abordada por revistas de habla hispana (las que en mayoría se encuentran indexadas en Redalyc), con este hallazgo, se pretendió establecer condiciones mínimas de calidad para posterior a ello realizar los análisis respectivos.

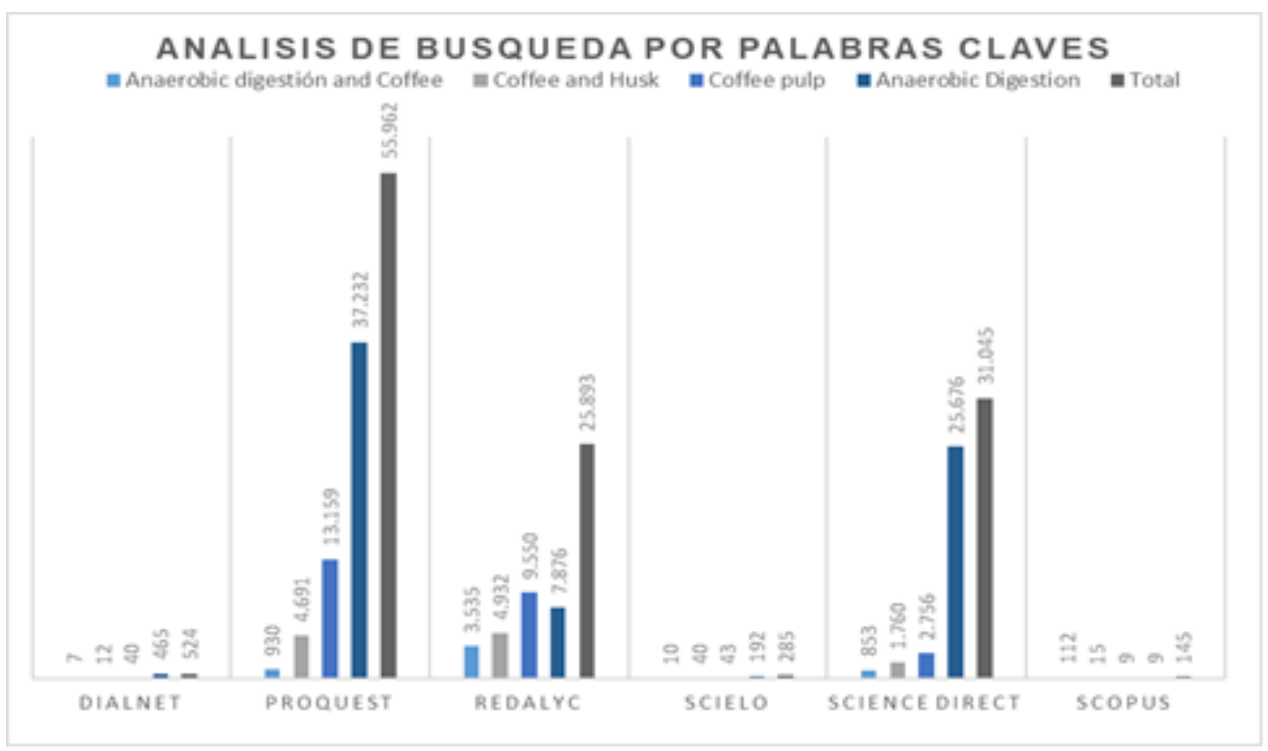

Figura 3. Análisis de búsqueda por palabras claves. Fuente: autores

Otro aspecto relevante, fue la combinación de palabras claves "Coffee pulp" y Anaerobic digestión" las cuales presentaron la mayor cantidad de referencias bibliográficas en el $90 \%$ de las bases de datos consultadas. Al revisar preliminarmente los resultados de la búsqueda conforme a la variable respuesta, se pudo evidenciar que al momento de seleccionar la pertinencia de los documentos las bases de datos con mejores contenidos fueron ScienceDirect, Scopus y Dialnet aportando un total de 28 artículos 
científicos de los 50 preseleccionados para el desarrollo de la investigación. Al finalizar esta etapa, se preseleccionaron 59 artículos los cuales fueron producto de la búsqueda basados en palabras claves y buscadores booleanos. Seguidamente, y de acuerdo con la metodología PRISMA se analizaron los artículos seleccionados y se asignó una puntuación por elementos (título, DOI, fundamento, metodología, selección de estudios, recopilación de datos, riesgo de sesgo y conclusiones en todos los ítems la escala de puntuación fue la misma, esto permitió tomar como referencia los artículos con mejor puntuación y realizar las conclusiones a partir de los mismos.

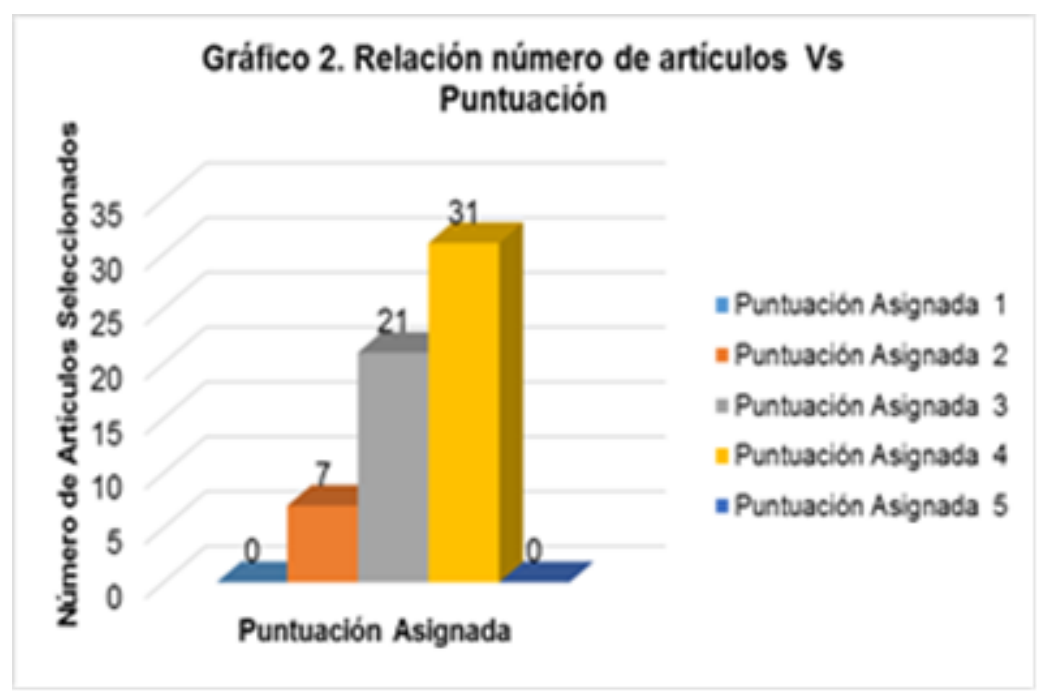

Figura 4. Relación número de artículos vs puntuación

De los 59 artículos de la consulta, se establece que solo 31 de ellos, cumplen con condiciones mínimas requeridas para la construcción de conclusiones requeridas en la investigación. Es importante destacar que las consultas previas realizadas permitieron establecer de forma 


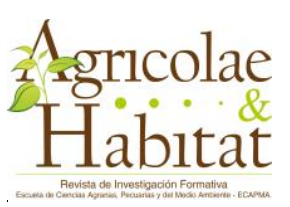

anticipada las potenciales variables que afectan de manera directa la digestión anaeróbica: temperatura, pH, agitación o mezclado, entre otras. Variables que afectan la digestión anaerobia

Existen numerosos estudios que respaldan cuales con las variables más significativas dentro del proceso de digestión anaerobia se encuentran:

A. Temperatura. La temperatura influye considerablemente en el crecimiento y supervivencia de microorganismos, sin embargo, el tratamiento anaeróbico es posible en todos los tres rangos de temperatura (psicrofílica, mesofílica y termofílica), usualmente la baja temperatura conduce a declinar en la velocidad de crecimiento y actividad metanogénica. La digestión anaerobia termofílica $\left(55-70^{\circ} \mathrm{C}\right)$ tiene una ventaja sobre la digestión mesofílica $\left(37^{\circ} \mathrm{C}\right)$ resultando en una velocidad de reacción más rápida y mayor productividad comparada con la digestión anaerobia. mesofílica. las condiciones óptimas para digestión anaerobia. podría ser hidrólisis/acidogénesis termofílica y metanogénesis mesofílica (Mao et al., 2015).

Según estudios desarrollados por Parra, (2015), el tratamiento anaeróbico es posible en todos los tres rangos de temperatura (psicrofílica, mesofílica y termofílica), usualmente la baja temperatura conduce a declinar en la velocidad de crecimiento y actividad metanogénica. La digestión anaerobia. termofílica $\left(55-70^{\circ} \mathrm{C}\right)$ tiene una ventaja sobre la digestión mesofílica $\left(37^{\circ} \mathrm{C}\right)$ resultando en una velocidad de reacción más rápida y mayor productividad comparada con la digestión anaerobia mesofílica. Castellón et, al (2015) afirmó que la digestión anaerobia puede ocurrir en la gama termofílica entre $37-65^{\circ} \mathrm{C}$, con un óptimo en las proximidades de $\operatorname{los} 55^{\circ} \mathrm{C}$, sin embargo, las bacterias 
metanogénicas digieren la materia orgánica más eficientemente en el rango mesofílico que puede ser alcanzado por la fase líquida, no solamente por efecto de la temperatura ambiental sino también por la temperatura interna. Mientras que Romero et al, (2013) asegura que la mayor eficiencia de conversión de la mezcla de la pulpa se obtiene en los rangos de temperatura de $20^{\circ} \mathrm{C}$ a $34.2^{\circ} \mathrm{C}$, en la cual las bacterias metano génicas digieren la materia orgánica en forma más eficiente. La estructura de las comunidades microbianas activas a las dos temperaturas óptimas es bastante diferente. Un cambio de temperatura mesofílica a termofílica (o viceversa) puede resultar en una disminución marcada en producción de biogás. Incluso pequeños cambios en temperatura, de $35^{\circ} \mathrm{C}$ a $30^{\circ} \mathrm{C}$ a de $30^{\circ} \mathrm{C}$ a $32^{\circ} \mathrm{C}$ han mostrado reducir la velocidad de producción de biogás (Ward et al., 2008).

Tabla 3. Rangos de temperatura óptimos para el desarrollo de los microrganismos en cada etapa del proceso de digestión anaerobia.

\begin{tabular}{|c|c|c|c|c|c|}
\hline Etapa & $\begin{array}{c}\text { Rango de } \\
\text { Temperatura } \\
\text { reportado }\end{array}$ & Referencia & Etapa & $\begin{array}{c}\text { Rango de } \\
\text { Temperatura } \\
\text { reportado }\end{array}$ & Referencia \\
\hline Hidrólisis & $55^{\circ} \mathrm{C}$ & $\begin{array}{c}\text { (Salazar., et al } \\
\text { 2012) }\end{array}$ & Metanogénesis & $30-46^{\circ} \mathrm{C}$ & $\begin{array}{c}\text { (Corrales., et al } \\
2015)\end{array}$ \\
\hline Hidrólisis & $33^{\circ} \mathrm{C}$ & $\begin{array}{l}\text { (Vásquez, } \\
\text { 2015) }\end{array}$ & Metanogénesis & $35^{\circ} \mathrm{C}$ & $\begin{array}{c}\text { (Jung., et al } \\
\text { 2012) }\end{array}$ \\
\hline Acidogénesis & $30^{\circ} \mathrm{C}$ & $\begin{array}{c}\text { (Bergamo., et } \\
\text { al 2009) }\end{array}$ & Metanogénesis & $27-34^{\circ} \mathrm{C}$ & $\begin{array}{l}\text { (Matamoros, } \\
\text { 2016) }\end{array}$ \\
\hline Acidogénesis & $55^{\circ} \mathrm{C}$ & $\begin{array}{c}\text { (Hernández \& } \\
\text { Delgadillo, } \\
\text { 2011) }\end{array}$ & Metanogénesis & $35^{\circ} \mathrm{C}$ & $\begin{array}{c}\text { (Bergamo., et al } \\
\text { 2009) }\end{array}$ \\
\hline Acidogénesis & $30-37^{\circ} \mathrm{C}$ & $\begin{array}{l}\text { (Corrales., et } \\
\text { al 2015) }\end{array}$ & Metanogénesis & $55^{\circ} \mathrm{C}$ & $\begin{array}{c}\text { (Hernández \& } \\
\text { Delgadillo, 2011) }\end{array}$ \\
\hline Acidogénesis & $37^{\circ} \mathrm{C}$ & $\begin{array}{l}\text { (Guardia., et } \\
\text { al 2010) }\end{array}$ & Metanogénesis & $37^{\circ} \mathrm{C}$ & $\begin{array}{c}\text { (Guardia., et al } \\
\text { 2010) }\end{array}$ \\
\hline Acidogénesis & $55^{\circ} \mathrm{C}$ & $\begin{array}{l}\text { (Jung., et al } \\
\text { 2012) }\end{array}$ & & & \\
\hline
\end{tabular}


De acuerdo con lo anterior, es posible concluir que las mejores condiciones según los referentes consultados en el caso de la temperatura para la digestión anaerobia son aquellas que se encuentran en un rango mesofílico, es decir, entre $30^{\circ} \mathrm{C}$ a $40^{\circ} \mathrm{C}$. Puesto que las bacterias metanogénicas digieren la materia orgánica más eficientemente en este rango, favoreciendo su desarrollo y metabolismo. Otros rangos de temperatura pueden ser implementados en el proceso, sin embargo, los resultados pueden verse afectados al momento de medir la producción de biogás.

B. Potencial de Hidrógeno - $\mathrm{pH}$. Otro factor limitante en el proceso de digestión anaerobia es el $\mathrm{pH}$, ya que este afecta directamente la actividad enzimática de los microrganismos, los resultados encontrados en los artículos consultados revelan que la mayoría de los microrganismos se desarrollan óptimamente en $\mathrm{pH}$ entre 6.8 a 7.2. No obstante, este factor no pude generalizarse, debido a que está directamente influenciado por el tipo de sustrato utilizado. En primera instancia se define el $\mathrm{pH}$ como una medida de la concentración de hidrógeno expresado en términos logarítmicos. Los valores del $\mathrm{pH}$ se reducen a medida que la concentración de los iones de hidrógeno incrementa, variando entre un rango de 0 a 14. Los valores por debajo 7.0 son ácidos, valores superiores a 7.0 son alcalinos y/o básicos, mientras que los que rondan 7.0 son denominados neutros. (Meza, 2011). Existen varios métodos para medir el valor del $\mathrm{pH}$, dentro de los más destacados se encuentran: papel tornasol o tiras medidoras, $\mathrm{pH}$ metro digital, gotas indicadoras o rojo fenol, entre otros (González, 2011).

Según estudios desarrollados por Guardia, (2012) el pH es una importante variable para la fase de hidrólisis-acidificación, los valores de 
$\mathrm{pH}$ inferiores a 5 afectan considerablemente la producción de los ácidos orgánicos, siendo los valores cercanos a pH 6 los más adecuados para obtener altos niveles de esos compuestos en esta fase. Siddique et al, (2018) coincide en afirmar que el pH tiene una influencia importante en la digestión anaerobia ya que afecta la solubilización de materias orgánicas. El máximo rendimiento de metano se ha observado manteniendo un $\mathrm{pH}$ entre 6,8 y 7.2. Microorganismos hidrogenantes y acidogénicos prefieren valores dentro del rango de 5.5 y 6.5. Sin embargo, el pH óptimo para el microorganismo metano génico está cerca 7.0, acercándose a lo expuesto por Matamoros, (2016) quien afirma que las reacciones anaeróbicas son altamente dependientes del $\mathrm{pH}$, siendo el rango óptimo para las bacterias metano génicas entre 6.8 a 7.2. Pérez et al, (2018) afirma que las condiciones óptimas para la producción de metano a partir de mucílago de café son pH 8.2 y concentración de azúcar $27 \mathrm{gL}-1$.

Tal como se muestra en las referencias de investigaciones más recientes, se evidencia que los valores de $\mathrm{pH}$ son tendientes a trabajar en rangos un poco más ácidos, debido a que en las etapas de acidogénesis y acetogénesis se forman ácidos carboxílicos o ácidos débiles, dentro de los que se destacan el ácido acético y el ácido propanoico; e incluso en la etapa metanogénica, es evidente la formación de estados de equilibrio, dándose consigo la formación del ácido carbónico, sin embargo, cabe recordar que este tipo de sistemas de equilibrio con el ion carbonato tienden a alcalinizar los sistemas, por ello, es de gran importancia conocer la acidez/basicidad del sustrato de partida. Se tienen reportes que el café posee una acidez que oscila entre 1-4.84, por lo que es importante establecer que dependiendo del tipo de residuos se busquen reguladores 
de $\mathrm{pH}$ con la capacidad amortiguadora suficiente para controlar el sistema. En la Tabla 4 se explican claramente los distintos estudios reportados para este residuo agroindustrial y los rangos de $\mathrm{pH}$ encontrados.

Tabla 1. Rangos de pH óptimos para la digestión anaerobia reportados por distintos autores.

\begin{tabular}{|c|c|c|c|}
\hline Rango de pH & Referencia & Rango de pH & \begin{tabular}{c} 
Referencia \\
\hline 6.0
\end{tabular} \\
\hline $6.8-7.2$ & (Guardia, 2012) & $6.6-7.6$ & (Castellón., et al 2015) \\
\hline $6.8-7.2$ & (Siddique et., al 2018) & 7.0 & (Parra, 2015) \\
\hline 8.2 & (Matamoros, 2016) & 7.0 & (García, 2014) \\
\hline $6.8-7.3$ & (Iswanto et al, 2017) & 7.0 & (Cendales \& Jiménez, 2015) \\
\hline $6.5-7.5$ & (Balseca, et al 2011) & $6.5-7.5$ & (Quintero., et al 2012) \\
\hline $6.5-7.7$ & (Parra., et al 2014) & $6.5-7.5$ & (Morales \& Mejía, 2015) \\
\hline
\end{tabular}

C. Agitación o mezclado. El mezclado permite mantener la mayor cantidad de alimento en contacto con las bacterias, reducir el volumen ocupado por materiales orgánicos e inorgánicos sedimentables y homogenizar la temperatura y la concentración de la mezcla. Es todo, con el fin de acelerar el proceso de ruptura de los sólidos volátiles y la producción de metano (Morales, 2010). Sin embargo, el mezclado no debe ser demasiado fuerte ya que podría destruir los flóculos o agregados de bacterias, necesarios para mantener un proceso estable (Flotats \& Campos, 2004).

D. Poder calorífico. El poder calorífico expresa la energía máxima que puede liberar la unión química entre el combustible y el comburente y es igual a la energía que mantenía unidos los átomos en las moléculas de combustible (energía de enlace), menos la energía utilizada en la formación de nuevas moléculas en las materias (generalmente gases) 
formadas en la combustión. La magnitud del poder calorífico puede variar según como se mida. Según la forma de medir se utiliza la expresión poder calorífico superior (abreviadamente, PCS) y poder calorífico inferior (abreviadamente, PCI) (Gómez., et al, 2017).

De acuerdo con el estudio realizado por Castellón, (2015) el estiércol bovino presenta un poder calorífico equivalente a $71,86 \mathrm{kcal} / \mathrm{m} 3$, el estiércol porcino de $87,28 \mathrm{kcal} / \mathrm{m} 3$ y la pulpa de café de $0,54 \mathrm{kcal} / \mathrm{m} 3$ obteniendo como resultado que el estiércol porcino es el que presenta mayor poder calorífico en comparación con los otros materiales orgánicos y por ende mayor producción de biogás. Por su parte, Balseca y Cabrera, (2011) señalan que el estiércol porcino, produce $30 \mathrm{~L}$ de biogás por kg de estiércol, el bovino $20 \mathrm{~L}$ de biogás por kg de estiércol y la pulpa de café $128 \mathrm{~L}$ de biogás por $\mathrm{kg}$ de sustrato. Cabe recordar que la importancia de que el biogás posea un buen poder calorífico es su capacidad para poder ser útil como comburente y que permita que la tecnología sea promisoria, sin embargo, a la fecha no hay reportes concluyentes acerca del poder calorífico de los residuos para la digestión anaerobia.

E. Inoculación. La inoculación consiste en introducir artificialmente una proporción de muestra (inoculo) en un medio adecuado, con el fin de iniciar un cultivo microbiano para su desarrollo y multiplicación (Santambrosio, 2009).

La importancia de inocular o no depende del tipo de efluente que será tratado, la inoculación del sistema puede ser necesaria o no. Sin embargo, gran parte de los residuos a ser tratados carecen de la población bacteriana necesaria para el correcto desempeño de los reactores. La calidad y cantidad de este son factores importantes que definen la 
duración del período de arranque y desempeño del digestor, ya que es ahí donde la biomasa activa crece y adquiere las propiedades necesarias para la remoción de la materia orgánica, pudiendo reducir el tiempo de digestión. Este tiempo será corto si el inoculo posee células jóvenes y activas. Varios autores han evaluado la concentración de inóculo en la muestra y han coincidido en que valores entre 5 y $10 \%$ en volumen aseguran un proceso eficiente. Los sustratos más ampliamente utilizados como inóculos para la DA por su concentración en bacterias metanogénicas han sido los purines de cerdo, rumen y lodos de depuración (Córdoba., et al, 2014).

Un claro ejemplo, es el estudio desarrollado por Schlegel, et al (2008), mostró un incremento significativo en la productividad del biogás cuando se mezclaron excretas animales (vacunas y porcinas) con residuos industriales de alimentos (forraje de remolacha, maíz, sorgo dulce y cebada).

Investigaciones realizadas por Olvera \& Gutiérrez, (2010) con residuos de pulpa de café, recomiendan el estiércol de ganado vacuno o rumen como inóculo para el funcionamiento del sistema. Guardia Puebla (2012) aplicó como inóculo a este tipo de residuos, lodo granular proveniente de un reactor que trataba aguas residuales de una fábrica de conservas de jugo. Sandoval., et al (2015), reportó un mayor rendimiento de biogás cuando uso una concentración de $10 \%$ de inóculo con relación al 3\%. Obteniendo un rendimiento final de $15 \mathrm{~L}$ de biogás/kg de sustrato.

García, (2014) afirmó que la pulpa de café no contiene una población de bacterias metanogénicas, que son las responsables de la descomposición de la materia orgánica para la producción de gas, por esta razón se debe 
de hacer un inoculo con estiércol de ganado bovino ya que este posee gran población de bacterias metanogénicas.

Un estudio desarrollado por Montenegro y Rojas, (2016) señala que la mezcla de residuos de alimentos con diferentes mezclas de estiércol genera un aumento en el rendimiento de producción de metano, en comparación con la digestión de estiércol o residuos de alimentos y de actividades pecuarias evaluados individualmente. La producción anual de metano generado en diferentes plantas centralizadas utilizando sustratos como estiércol bovino, estiércol de aves de corral y pollos, residuos orgánicos e industriales es de 7,3 106 m3/año, donde gracias a esta mezcla se aumentó el BMP en un 80 \%. Las mezclas realizadas generalmente utilizan estiércol principalmente de especies bovinas, residuos vegetales y residuos lignocelulósicos. En estos casos el potencial de dos plantas generadoras, de 2,4 105 m3/año y 4,5 104 m3/año, se vio influenciado significativamente al agregar a la mezcla estiércol bovino lo cual produjo un aumento exponencial en la producción de biogás. La adición de residuos de vegetales en un $2,5 \%$ de volumen y de residuos de granjas para estiércol de cerdo presenta un aumento de $124 \%$ en la producción de metano a diferencia del potencial obtenido con la digestión del estiércol por separado gracias a la reducción de la humedad al aumentar dicho residuo. El aumento en la producción de biogás en las mezclas mencionadas se debe a que la presencia de estiércol produce un ajuste en la relación $\mathrm{C} / \mathrm{N}$, la cual es fundamental a la hora de producir biogás. Otros autores como Codignole et al, (2017) mencionan que la producción de biogás a partir de la fracción liquida de café molido mezclado con estiércol fresco de vaca ha demostrado ser factible con una alta concentración de metano. De acuerdo con los autores tales como 
Rosa, (2015) y Sandoval et al, (2015) a mayor concentración de inoculo se incrementa la producción de biogás del proceso de digestión anaerobia de pulpa de café en sustrato sólido. Otros autores como Siddique, (2018) hacen énfasis en que la integración de modelos cinéticos y termodinámicos, así como la adición de aditivos inorgánicos y biológicos pueden mejorar el proceso de optimización del biogás.

De acuerdo con el estudio desarrollado por Bautista, (2010) las mezclas con sustratos como gallinaza con agua produjeron más biogás en menos tiempo que otros sustratos como cascaras de plátano, suero de leche y pulpa de café con agua miel. La cáscara de plátano también funcionó adecuadamente, a pesar de encontrarse en algunos momentos con un $\mathrm{pH}$ más bajo de lo deseado. Sin embargo, tanto en las tres mezclas de residuos del despulpado de café como en el suero de leche aparecieron diversos problemas de mayor magnitud relacionados con el $\mathrm{pH}$ (demasiado ácido). En los ensayos con la pulpa de café y las aguas mieles se observó que se necesitaba mucho tiempo de retención para producir poco biogás. Esto puede ser debido a la cantidad de azúcares presentes en estos residuos, por lo que sería mucho más interesante su estudio para producir bioetanol en lugar de biogás.

Castellón, Martínez y Gutiérrez, (2015) encontraron que el estiércol porcino presenta un mayor poder calorífico $87,28 \mathrm{kcal} / \mathrm{m} 3$ en comparación con el estiércol bovino que presentó un poder calorífico equivalente a $71,86 \mathrm{kcal} / \mathrm{m} 3$ y la pulpa de café de 0,54 kcal/m3. En conclusión, la mezcla que produjo más biogás en menos tiempo fue la del estiércol porcino, sin embargo, esta necesitaba mayor cantidad de desecho. Otros estudios reportan una producción de $25 \mathrm{~L}$ de biogás por $1 \mathrm{~kg}$ de pulpa fresca en los biodigestores y un poder calorífico del biogás de $21,46 \mathrm{~kJ} / \mathrm{L}$, 
con un contenido de metano de 60 \% (Rodríguez, 2018). Por otro lado, de acuerdo con estudios realizados por Balseca y Cabrera (2011), en ensayos similares obtuvieron $128 \mathrm{~L}$ de biogás por kilogramo de pulpa de café. A su vez, Calle y Arcila (1974) citados por Rosa, R. (2015), reportan rendimientos de $25 \mathrm{~L}$ de biogás por kilogramo de pulpa fresca alimentada a los digestores. Lorenzo y Obaya (2005) afirman que la cantidad de gas producido es muy variable, aunque generalmente oscila alrededor de los 350 L/kg de sólidos degradables. Estos datos muestran una notable diferencia entre ellos.

F. Factores de inhibición. El amoniaco $(\mathrm{NH} 3)$ y el amonio $(\mathrm{NH} 4+)$, se acumula durante el rompimiento de proteínas y es el principal inhibidor de los procesos de D.A a concentraciones cerca de $1700-1800 \mathrm{mg} / \mathrm{L}$ pueden inhibir inóculos sin aclimatar los niveles de amonio se pueden aclimatar a $5000 \mathrm{mg} / \mathrm{L}$ (Yenigun \& Demirel, 2013). El tiempo de retención hidráulico ha sido investigado debido a su efecto sobre la productividad de biogás; se ha reportado ser uno de los parámetros más importantes afectando significativamente la ecología microbiana en reactores. Concentraciones altas de alcalinidad por encima de $6500 \mathrm{mg} / \mathrm{L}$ y valores de $\mathrm{pH}$ superiores a 7,4 sugieren que la actividad bacteriana puede verse afectada debido a varios efectos tóxicos de alcalinidad (Parra, 2015).

Las bacterias en el proceso de D.A. requiere micronutrientes y elementos traza como nitrógeno, fósforo, sulfuros, potasio, calcio, magnesio, hierro, níquel, cobalto, zinc, manganeso y cobre para el crecimiento óptimo. A pesar de que estos elementos son necesarios en concentraciones extremadamente bajas, la ausencia de estos tiene efectos adversos sobre el crecimiento y rendimiento microbiano. Las bacterias formadoras de metano tienen concentraciones internas relativamente altas de hierro, 
níquel y cobalto. La velocidad de carga orgánica (V.C.O) representa la cantidad de alimento suministrado a un digestor por día bajo condiciones continuas de alimentación. La inhibición bacteriana se produce debido a una alta velocidad de carga orgánica (V.C.O) provocando actividad en la hidrólisis/acidogénesis más que la actividad bacteriana en la metanogénesis, de esta manera se incrementa la producción de ácidos grasos volátiles (AGV), lo cual posteriormente provocaría una acidificación irreversible. Posteriormente, el pH del digestor disminuiría y el proceso de hidrólisis sería inhibido (Andreas \& Kornaros, 2015; Rizvi et al., 2015).

G. Relación carbono: nitrógeno $(\mathrm{C} / \mathrm{N})$. La relación óptima de $\mathrm{C} / \mathrm{N}$ proporciona nutrientes suficientes para los microorganismos, maximizando la producción de biogás. Los valores de $\mathrm{C} / \mathrm{N}$ más bajos de lo requerido conducen a valores más altos en las concentraciones de amoniaco, lo que impiden el crecimiento microbiano. El proceso de digestión anaerobia es más estable cuando la relación $\mathrm{C} / \mathrm{N}$ varía de 20 a 30 , teniendo como punto óptimo una relación de 17:1. Mientras tanto, Bilhate et al, (2018) asegura que las cascaras de café presentan una relación ideal de $\mathrm{C} / \mathrm{N}$ para la digestión anaeróbica de 25 . El mucilago, sin embargo, presenta un valor más bajo que el recomendado, entre 20-30, el cual puede necesitar cogestión de otros sustratos con una relación $\mathrm{C} / \mathrm{N}$ más alta. Morales, et al (2015) y Codignole et al, (2017) coindicen en afirmar que el carbono y el nitrógeno son las fuentes principales de alimento de las bacterias formadoras de metano. Por tanto, la relación carbono: nitrógeno $(\mathrm{C} / \mathrm{N})$ tiene una gran importancia para el proceso fermentativo recomendándose un rango óptimo entre 20-30.

Otros autores como Montenegro y Rojas, (2016) afirman que la relación $(\mathrm{C} / \mathrm{N})$ es un factor determinante en la producción de metano ya que a 
valores bajos de $\mathrm{C} / \mathrm{N}$ incrementa el riesgo por exceso de nitrógeno y a su vez la inhibición del proceso, mientras que valores altos indican deficiencia de nitrógeno para la síntesis de biomasa. Valores entre 20-30 presentan resultados positivos e incrementan el rendimiento y el potencial de metano. En cuanto a los residuos vegetales de algunos cultivos, los elevados valores de $\mathrm{C} / \mathrm{N}$ y la escasez de elementos traza pueden afectar el correcto desarrollo del proceso por la producción de ácidos grasos y el decrecimiento del pH del sistema. De acuerdo a esto, y en general, para contrarrestar las deficiencias de los diferentes residuos se deben plantear procesos de co-digestión que ayudan a incrementar la producción de metano respecto a los potenciales individuales. En la co-digestión, los sustratos pueden estimular la síntesis de enzimas por la composición del material o la presencia de microorganismos que favorecen la sinergia del proceso.

De acuerdo con los resultados obtenidos se puede concluir que la relación $\mathrm{C} / \mathrm{N}$ es un parámetro de gran importante, ya que de estos depende el correcto suministro de alimento a los microorganismos y por ende la supervivencia de los mismos. La relación ideal puede estimarse en 17:1.

\section{CONCLUSIONES.}

La variación de la temperatura afecta significativamente la digestión anaerobia y la cantidad de biogás producido. Para que el proceso se mantenga estable, la temperatura del sustrato en el interior del digestor debe ser controlada ya que está no solo incide en el aspecto cinético (velocidad de consumo del sustrato, velocidad de crecimiento de biomasa) sino también en el aspecto termodinámico (conversión de sustrato a producto referente a las condiciones de equilibrio que se pueden lograr 
para una etapa determinada de la digestión anaerobia). Teniendo en cuenta lo anterior se puede concluir que el rango óptimo para la digestión anaerobia esta entre 30 a $40{ }^{\circ} \mathrm{C}$, este favorece el crecimiento de las bacterias metanogénicas por lo tanto la degradación de la materia orgánica y la producción de biogás.

La alta acidez no permite la actividad de las bacterias al interior del biodigestor, detiene la acción de las enzimas y afecta considerablemente la producción de ácidos orgánicos, siendo un factor limitante al momento de la producción de biogás. Los resultados encontrados dentro de la investigación permiten concluir que el pH óptimo para el correcto desempeño del sistema se encontró en un rango entre 6.8 a 7.2.

El uso de inóculos presenta muchas ventajas que favorecen la estabilidad del digestor, sin embargo, se debe verificar que la concentración de solidos presentes no afecte la mezcla y homogeneidad en el sistema, y por lo tanto no sea un obstáculo al evaluar el desempeño de este.

La pulpa de café al igual que otros residuos agroindustriales presenta un alto potencial de aprovechamiento gracias a su variada composición química, viéndose reflejado en la diversidad de alternativas existentes para su reutilización. Es posible obtener de estas, energías alternativas como Biogás, Bioetanol y Biomasa, previniendo impactos negativos por el inadecuado uso de estos.

\section{BIBLIOGRAFÍA.}

Baêta, B. E. L., Cordeiro, P. H. de M., Passos, F., Gurgel, L. V. A., de Aquino, S. F., \& Fdz-Polanco, F. (2017). Steam explosion pretreatment improved the biomethanization of coffee husks. Bioresource Technology.DOI: 
Buitrago, C. M. (2015). Trabajo de grado: evaluación del desempeño de un biodigestor para el tratamiento de la mezcla agua-mucílago de café obtenidas por desmucilaginador mecánico. Obtenido en: Trabajo

Clavijo, (2015). Universidad Nacional de Colombia. Evaluación del proceso de digestión anaeróbica de vinaza pretratada con procesos avanzados de oxidación como alternativa energética de implementación tecnológica en un proceso de producción de etanol a partir de caña de azúcar. http://www.bdigital.unal.edu.co/48678/1/1113623316.2015.pdf

Cendales \& Jiménez. (2015). Modelamiento computacional de la producción de energía renovable a partir del biogás mediante la codigestión anaeróbica de la mezcla de residuos cítricos y estiércol bovino. http://www.scielo.org.co/pdf/ean/n77/n77a02.pdf

Córdoba, Fernández \& Santalla. (2014). Influencia del inóculo en la digestión anaeróbica de purín de cerdo. Vol, 2. ISBN 978-987-29873-0-5. Argentina. https://www.researchgate.net/publication/268386719 Influencia del inoculo en la digestion anaerobica de purin de cerdo.

Corrales, et al, (2015). Bacterias anaerobias: procesos que realizan y contribuyen a la sostenibilidad de la vida en el planeta. http://www.scielo.org.co/pdf/nova/v13n24/v13n24a06.pdf.

Corro, G., Pal, U., \& Cebada, S. (2014). Enhanced biogas production from coffee pulp through deligninocellulosic photocatalytic pretreatment. Energy Science and Engineering. DOI: https://doi.org/10.1002/ese3.44

Dandikas, V., Heuwinkel, H., Lichti, F., Eckl, T., Drewes, J. E., \& Koch, K. (2018). Correlation between hydrolysis rate constant and chemical composition of energy crops. Renewable Energy. DOI: https://doi.org/10.1016/j.renene.2017.10.100 
Del Real Olvera, J., \& Islas Gutiérrez, J. (2010). Biodegradacion anaerobia de las aguas generadas en el despulpado del cafe. Rev. Colomb. Biotecnol.

Demirel, B.; Yenigun, O \& Onay. (2005). Anaerobic treatment of dairy wastewaters: a review. Process Biochemistry, 40, 2583-2595DOI: 10.15446/rev.colomb.biote

G., Jaromír Klemeš, J., Yen Liew, P., Shin Ho, W., Shiun Lim, J., Widjaja, T. Rachmania Juliastuti, S. (2017). Methane Production from Coffee Pulp by Microorganism of Rumen Fluid and Cow Dung in Co-digestion. In chemical engineering transactions (Vol. 56). DOI: https://doi.org/10.3303/CET1756245

Peñaranda González, Laura Victoria; Montenegro Gómez, Sandra Patricia; Giraldo Abad, Paula Andrea. Aprovechamiento de residuos agroindustriales en Colombia. Revista de Investigación Agraria y Ambiental, [S.I.], v. 8, n. 2, p. 141 - 150, june 2017. ISSN 2145-6453. Disponible en: <http://hemeroteca.unad.edu.co/index.php/riaa/article/view/2040/2251>. Fecha de acceso: 06 may. 2019 DOI: https://doi.org/10.22490/21456453.2040

González \& Gómez. (2017). Sustratos y producción de biogás en biodigestores. Una revisión sistemática. http://editorial.ucentral.edu.co/ojs uc/index.php/Ingeciencia/article/view/235 $\underline{2}$

González, C. (2011). Calidad

del agua. http://academic.uprm.edu/gonzalezc/HTMLobj-862/maguaph.pdf

Guardia, Y. (2012). Estudio de la digestión anaerobia en dos fases para el tratamiento de las aguas residuales de despulpe del beneficiado húmedo del café. Universidad politécnica de Madrid escuela técnica superior de ingenieros agrónomos. http://oa.upm.es/14684/1/YANS GUARDIA PUEBLA.pdf 
Gurram, R., Al-Shannag, M., Knapp, S., Das, T., Singsaas, E., \& Alkasrawi, M. (2016). Technical possibilities of bioethanol production from coffee pulp: A renewable feedstock. Clean Technologies and Environmental Policy. DOI: https://doi.org/10.1007/s10098-015-1015-9

Flotats \& Campos. (2004). Procesos biológicos: La digestión anaerobia y el compostaje.

https://www.researchgate. net/publication/304771327 Procesos biologicos La digestion anaerobia y el compostaje

Hernández, M. \& Delgadillo, L. (2011). Aplicación del modelo ADM1 en la digestión anaerobia de aguas residuales y desechos sólidos. Revista Tumbaga, 6, 29-42. http://revistas.ut.edu.co/index.php/tumbaga/article/view/46

Hikichi, S. E., Andrade, R. P., Dias, E. S., \& Duarte, W. F. (2017). Biotechnological applications of coffee processing by-products. In Handbook of Coffee Processing By-Products: Sustainable Applications. DOI: https://doi.org/10.1016/B978-0-12-811290-8.00008-6

Hughes, S. R., Qureshi, N., López-Núñez, J. C., Jones, M. A., Jarodsky, J. M., Galindo-Leva, L. Á., \& Lindquist, M. R. (2017). Utilization of inulin-containing waste in industrial fermentations to produce biofuels and bio-based chemicals. World Journal of Microbiology and Biotechnology. DOI: https://doi.org/10.1007/s11274-017-2241-6

Kazagic, A., Music, M., Smajevic, I., Ademovic, A., \& Redzic, E. (2016). Possibilities and sustainability of "biomass for power" solutions in the case of a coal-based power utility. Clean Technologies and Environmental Policy.DOI: https://doi.org/10.1007/s10098-016-1193-0

Londoño, H. 2017. Aprovechamiento de pulpa de café para la producción de biogás en un reactor de flujo Pistón. 
Lora, E. S., \& Andrade, R. V. (2009). Biomass as energy source in Brazil. Renewable and Sustainable Energy Reviews. DOI: https://doi.org/10.1016/j.rser.2007.12.004

Lyakurwa, F. S. (2016). Assessment of the energy potential of crop residues and animal wastes in Tanzania. Independent Journal of Management \& Production. https://doi.org/10.14807/ijmp.v7i4.473

Llamas, M. (2014). Estudio del efecto del rango de temperatura sobre la producción de bio-hidrógeno por digestión anaerobia a partir de residuos orgánicos.

https://rodin.uca.es/xmlui/bitstream/handle/10498/17868/TFGBiotecnolog\%C 3\%ADa-MercedesLlamas.pdf

Mao, C.; Feng, Y.; Wang, X \& Ren, G. (2015). Review on research achievements of biogas from anaerobic digestion. Renewable and Sustainable Energy Reviews, 45,540-555

Matamoros, C. (2016). Universidad Politécnica de Madrid escuela técnica superior de ingenieros industriales departamento de ingeniería mecánica y fabricación investigación sobre fermentaciones metánicas de desechos estacionales.

Meneses-Jácome, A., Diaz-Chavez, R., Velásquez-Arredondo, H. I., CárdenasChávez, D. L., Parra, R., \& Ruiz-Colorado, A. A. (2016). Sustainable Energy from agro-industrial wastewaters in Latin-America. Renewable and Sustainable Energy Reviews.DOI: https://doi.org/10.1016/j.rser.2015.12.036

Mendoza Velásquez, S., Cano Muñoz, J., \& Rojas Sánchez, F. (2015). Acción comunitaria frente al fenómeno del cambio climático, en el páramo de la región del Guavio, Cundinamarca, Colombia. Revista de Investigación Agraria y Ambiental, 6(1), 265 - 279. DOI: https://doi.org/10.22490/21456453.1286 
Meza, M. (2011). Disturbios del estado ácido-básico en el paciente crítico. http://www.scielo.org.pe/pdf/amp/v28n1/a08v28n1.pdf

Ngumah, C. C., Ogbulie, J. N., Orji, J. C., \& Amadi, E. S. (2013). Biogas potential of organic waste in Nigeria. Journal of Urban and Environmental Engineering. DOI: https://doi.org/10.4090/juee.2013.v7n1.110116

Parra., et al. (2014). Influencia del pH sobre la digestión anaerobia de biorresiduos de origen municipal. http://www.scielo.org.co/pdf/rudca/v17n2/v17n2a27.pdf

Passos, F., Cordeiro, P. H. M., Baeta, B. E. L., de Aquino, S. F., \& Perez-Elvira, S. I. (2018). Anaerobic co-digestion of coffee husks and microalgal biomass after thermal hydrolysis. Bioresource.

Reyes. (2017). Generación de biogás mediante el proceso de digestión anaerobia, a partir del aprovechamiento de sustratos orgánicos. https://www.lamjol.info/index.php/FAREM/article/download/5552/5248

Rodríguez, N. (2013). Producción de alcohol a partir de la pulpa de café. http://biblioteca.cenicafe.org/bitstream/10778/541/1/arc064\%2802\%2978-

\section{3.pdf}

Romero Loaiza, R., Henry, R., \& Pari, M. (2013). Obtención de biogás como fuente de energía renovable a partir de los subproductos del café "obtaining of biogas as a source of renewable energy from the coffee byproducts." Rev. Investig. Altoandin (Vol. 15). https://studylib.es/doc/8108239/volumennumerado4-corregido.cdr

Rosa Cruz \& Fabiola Sandoval Salas Jorge Arturo Del Ángel Ramos Xalapa, D. D. (2015). Universidad veracruzana facultad de ingeniería mecánica y eléctrica.Technology. https://doi.org/10.1016/j.biortech.2017.12.071 


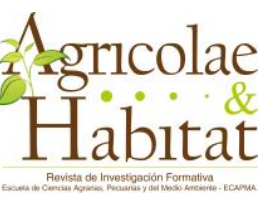

Rattan, S., Parande, A. K., Nagaraju, V. D., \& Ghiwari, G. K. (2015). A comprehensive review on utilization of wastewater from coffee processing. Environmental Science and Pollution Research. https://doi.org/10.1007/s11356-015-4079-5

Rojas-Sossa, J. P., Murillo-Roos, M., Uribe, L., Uribe-Lorio, L., Marsh, T., Larsen, N.Liao, W. (2017). Corrigendum to "Effects of coffee processing residues on anaerobic microorganisms and corresponding digestion performance" $\begin{array}{lllll}\text { [Bioresour. } & \text { Technol. } & 245 & \text { (2017) }\end{array}$ https://doi.org/10.1016/j.biortech.2017.11.030

Rouches, E., Zhou, S., Steyer, J. P., \& Carrere, H. (2016). White-Rot Fungi pretreatment of lignocellulosic biomass for anaerobic digestion: Impact of glucose supplementation. Process Biochemistry. https://doi.org/10.1016/j.procbio.2016.02.003

S. Ait Lhaj Lahcen; S. Ibn Ahme; Y. Joute; H. El Bari. (2018). Characterization and evaluation of methanogenic potential of coffee waste. Mater. Environ. Sci., 2018, Volume 9, Issue 2, Page 655-661. DOI: https://doi.org/10.26872/jmes.2018.9.2.72

Salas, F. S., Cruz, R. J. R., De Biogas En, P., Sólido, S., De, A. P., De Café, P.,Cuevas, C. (2015.). Producción de biogás en sustrato sólido a partir de pulpa de café. Enlace

Salazar, López \& Cano. (2012). Efecto del pH y la temperatura en la hidrólisis enzimática de subproductos de la industria bovina. https://www.redalyc.org/articulo.oa?id $=69525875002$

Sánchez, J. (2016). Universidad Politécnica de Madrid. Optimización de la agitación de un digestor anaerobio mediante mecánica de fluidos computacional. http://oa.upm.es/39549/1/Jesus Sanchez Rubal.pdf 
Siddique, M. N. I., \& Wahid, Z. A. (2018). Achievements and perspectives of anaerobic co-digestion: A review. Journal of Cleaner Production. https://doi.org/10.1016/j.jclepro.2018.05.155

Surendra, K. C., Takara, D., Hashimoto, A. G., \& Khanal, S. K. (2014). Biogas as a sustainable energy source for developing countries: Opportunities and challenges. Renewable and Sustainable Energy Reviews. https://doi.org/10.1016/j.rser.2013.12.015

Tatiana, K., Orozco, M., Sofía, A., Carpio, R., Iván; Rojas, C., Pardo, H. (2016). Biogas potential of agro-industrial residues generated in the department of Cundinamarca. DOI: https://doi.org/10.18273/revion.v29n2-2016002

Teperino, d. P. M., Ladeira Neto, m. A., Ferrarez, a. H., Gomes, a. T., Poubel, h. S., \& silva, e. D. S. Da. (2017). Desenvolvimento de digestor anaeróbio didático e testes de produção de biogás com resíduos da bovinocultura e cafeicultura. Acta Biomédica Brasiliensia. DOI: https://doi.org/10.18571/acbm.140.

Toro Calderón, J., Martínez Prada, R., \& Arrieta Loyo, G. (2013). Métodos de Evaluación de Impacto Ambiental en Colombia. Revista de Investigación Agraria y Ambiental, 4(2), 43-53. DOI: https://doi.org/10.22490/21456453.990

Vásquez, (2015). Etanol lignocelulósico, a partir de cascarilla de café, por medio de hidrólisis química-enzimática y fermentación". https://cdigital.uv.mx/bitstream/handle/123456789/41986/VazquezMoralesOs car. . pdf; jsessionid=6E94ACFA40298AEC2B4ECE2685999CFE? sequence $=1$

Ward, A. J.; Hobbs, P. J.; Holliman, P. J. \& Jones, D. L. (2008). Optimisation of the anaerobic digestion of agricultural resources. Bioresource Technology, 99 (17), 7928-7940.

Yadira Pérez-sariñana, B., Díaz-gonzález, A., León-rodriguez, A. DE, Saldañatrinidad, S., Del Carmen Pérez-luna, Y., Alberto Guerrero-fajardo, C., \& Sebastián, P. (2018). Methane production from coffee crop residues. Romanian 


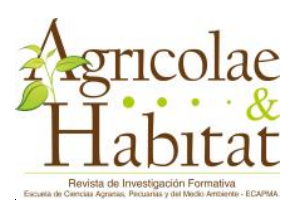

Biotechnological

Letters.

https://www.rombio.eu/docs/Sarinana\%20et\%20al.pdf

Zhang, Q., Hu, J., \& Lee, D. J. (2016). Biogas from anaerobic digestion processes: Research updates. Renewable Energy. https://doi.org/10.1016/j.renene.2016.02.029 